\title{
COMUNICAÇÃO E FORMAÇÃO EM MÍDIAS DIGITAIS: novas práticas sociais na formação de profesores de ciências
}

\author{
Communication and formation in digital media: \\ new social practices in the formation of Science teachers
}

Adriane Lizbehd Halmann ${ }^{1}$

\section{Resumo}

Atendendo a várias demandas contemporâneas de comunicação, difusão do conhecimento e construção colaborativa, utilizando mídias digitais e web, propomos a inserção de diários eletrônicos ( $b l o g s$ ) na formação de professores de Ciências Naturais na Universidade Federal da Bahia. Os diários da prática pedagógica são indicados por alguns autores como instrumento de registro e análise da prática, ou ainda como instrumento de pesquisa, apontando sempre sua potencialidade como instrumento de reflexão docente. Os resultados obtidos demonstram que os blogs podem ser uma forma de diário da prática pedagógica, possibilitando, além da reflexão individual, a reflexão conjunta, a formação de comunidades, a cooperação, a extrapolação do espaço-tempo da escola, a inserção de outras formas de conhecimento na prática escolar e nos indica outras práticas sociais e educacionais, transformando as formas de pensar a/na educação.

Palavras-chave: Blogs; Mídias digitais; Formação de professores; Reflexão docente; Práticas sociais.

\begin{abstract}
Taking care of some contemporaries demands of communication, diffusion of the knowledge and colaborative construction, used digital media and web, we consider the electronic diaries (blogs) in the formation of teachers of Sciences in the Universidade Federal da Bahia. The diaries of the practical pedagogical are indicated by some authors as a instrument of register and analysis of the practice, or as instrument for research, pointing always its potentiality as instrument to the teaching reflection. The results demonstrate that blogs can be a form of daily of the pedagogical practice making possible besides the individual reflection, the collective reflection, the formation of communities, the cooperation, the "go out" of the space-time of the school, the insertion of other forms of knowledge in the practical pertaining to school and in them it indicates social and educational practice others, transforming the forms to think the education.
\end{abstract}

Keywords: Blogs; Digital medias; Teachers formation; Teaching reflection; Social practice.

\footnotetext{
1 Professora substituta da Faculdade de Educação da Universidade Federal da Bahia, nas disciplinas Ensino de Ciências no I Grau e Projetos de Ensino de Ciências. Mestre em Educação (linha Currículo e InFormação)/UFBA. Participante do Grupo de Pesquisa Educação, Comunicação e Tecnologias. adriane_halmann@yahoo.com.br
} 


\section{Demandas contemporâneas}

A sociedade contemporânea, com todos os movimentos na web, a revolução da comunicação e da informação, as novas faces da ciência apontam-nos outras demandas para a formação dos professores da educação básica.

Os movimentos na web são o maior exemplo da alteração nas relações com o saber. Nela formam-se redes de compartilhamento de informações, de cooperação, de construção conjunta de saberes. A comunicação não-massiva é cada vez mais presente, do que decorre o boom de blogs, fotologs, sites de relacionamento, sites de escrita colaborativa, entre outros. Os "quinze minutos de fama" das mídias massivas foram substituídos por muitos instantes em uma rede complexa que se desdobra em várias relações entre pessoas e saberes.

Nesse sentido, não cabe mais à educação ser simplesmente transmissora de pacotes fechados de "verdades" prontas e acabadas, os ditos saberes científicos, assim inquestionáveis. Hoje temos boa informação ao alcance de alguns cliques. Mais do que isso: temos pessoas dispostas a compartilhar seus saberes para construir novas práticas.

Estas e outras demandas nos fazem voltar o olhar para a formação dos professores de Ciências: se a ciência, mais do que nunca, abre-se à reconstrução em comunidades colaborativas, qual a função deste professor nas escolas? Mais do que nunca, é necessário que estes se voltem para tais movimentos contemporâneos e os compreendam como uma forma mais coerente de construir suas práticas, fundamentando-se em informações atualizadas, comunicando-se melhor, construindo saberes com seus pares.

Desta forma, pudemos observar, por meio de novas práticas na Universidade Federal da Bahia, que se instituem, na formação de professores, movimentos sociais onde a comunicação e as mídias digitais apresentam-se como promissoras. Os professores em formação utilizam blogs e outras mídias na web como estratégias de comunicação, difusão do conhecimento, construção colaborativa e reflexão sobre a prática docente.

Esta prática surgiu da indicação de vários autores para as possibilidades dos diários da prática docente, como instrumento de registro e análise da prática, ou ainda como instrumento de pesquisa, apontando sempre para suas potencialidades à reflexão docente. O inovador nesta ação foi transpor as barreiras do papel e ressignificar os diários na web por meio dos blogs, onde se notou que, além de muitas das potencialidades dos diários da prática pedagógica, os blogs possibilitaram uma série de movimentos que, por meio da comunicação e das mídias digitais, indicam outras práticas sociais e educacionais, novas formas de fazer e pensar a educação básica e a formação dos professores.

\section{0 contexto}

Este artigo surge de movimentos iniciados com a disciplina de Ensino de Ciências Naturais (EDC270), que se propõe a realizar estudos e discussões sobre tópicos selecionados de Ciências Físicas e Biológicas e sua relação com a Saúde, Ciência, Tecnologia e Sociedade. Para tanto, a disciplina prevê análises sócio-políticometodológicas da Educação e do Ensino de Ciências, sua integração com as tecnologias, além de observações e intervenções no ensino das Ciências.

Para contribuir no processo de análise e compreensão da prática pedagógica, os alunos da disciplina devem realizar o registro sistemático de suas ações, no intuito de viabilizar o diálogo sobre situações vividas em sala de aula, possibilitando a reconstrução de conhecimentos, à luz de leituras, saberes prévios, situações vivenciadas e cotidianas, num processo dialético de ação-reflexão-ação.

Estes registros (os diários) foram realizados em blogs, sendo que cada aluno confeccionou o seu e ali foi imprimindo, processualmente, sua representação dos fatos. Os endereços dos blogs dos alunos envolvidos nesta disciplina estão agrupados em um blog da disciplina, mantido pela professora: http:// edc270.blogspot.com. Esta prática já se estabelece por dois semestres, 2006.1 e .2, sendo que aqui trazemos as análises dos movimentos executados nestes períodos.

\section{Os diários}

Existem diversas conceituações de diários. Cada conceituação traduz uma perspectiva, um contexto, um modo de ver suas aplicações. De 
maneira bastante elementar, temos que é comum a todos os diários:

- é um registro, geralmente de forma escrita;

- com algum ou diversos focos de algo que acontece(u);

- feito com alguma periodicidade.

Quando falamos de registro, é fundamental analisarmos a escrita e o escrever. É por meio da escrita que representamos as palavras, idéias, mensagens [...] de forma permanente ou semipermanente em um suporte. Esta mediação com um suporte externo faz com que a informação seja repassada sem a necessidade da presença física dos interlocutores, provocando um distanciamento espaço-temporal de quem escreve e quem lê. Bonilla (2005, p. 121) alerta que:

Não se pode confundir o escrever com a escrita, a ação com a obra finalizada. Escrever é provocação, ao pensar, um suave deslizar da reflexão, uma busca do aprender, o princípio da investigação.

Notamos que os diários alcançam estas duas formas: a escrita, enquanto obra finalizada, que amplia as potencialidades da disseminação da palavra, um suporte para comunicações assíncronas; e o ato de escrever, que vem antes do produto, é o processo de criação, reflexão, leitura, análise, é o fazer-fazendo-se. O suporte amplia a disseminação e torna os pensamentos partilháveis, uma forma de extensão da capacidade humana.

Ligando estas falas aos $b \log s^{2}$, nota-se que estes dois termos, por vezes, confundem-se um pouco: pelo caráter fluido dos blogs, a escrita torna-se, assim como o pensamento humano, temporário, suscetível de mudança. No caso dos blogs, o suporte modela o produto (a escrita) enquanto que a escrita (e todos os movimentos realizados pelos homens ali) modela o suporte (o ciberespaço), o que pode ser qualificado como uma das características da produção, da técnica e da cibercultura. Este fazer-fazendo-se se faz também com e para o outro, em um diálogo constante com o eu, com o leitor e com o suporte.

Assim, escrita e escrever articulam-se organicamente, sendo que com o registro, podemos reler, revisar, voltar atrás, recriar, reformular nossos pensamentos, que geram novas escritas. Isso traz também implicações cognitivas, uma vez que está diretamente ligado à leitura, à alfabetização e à criticidade do leitorescritor. Está ligado também à fala, à memória, à organização e à produção dos conhecimentos. Diria até que é uma ampliação de nossos sentidos.

Por meio da escrita e do escrever, o leitor não é somente um organismo apático que só recebe informações exteriores e as joga para dentro pelas suas janelas. Pelo contrário, por meio dos sentidos e das linguagens, ele processa estas informações, estabelece novas conexões, amplia para outros entornos contextos e situações. No caso dos blogs, identificamos a potencialização desta não-acomodação passiva de informações e da produção por meio da interação.

Quanto ao foco, interessa-nos analisar os diários como instrumento para reflexão. Além disso, os diários se prestam como instrumento de memória que permite reler e avaliar a evolução de certo(s) tema(s). É sempre uma representação, leituras pessoais sobre fatos, perspectivas de visão sobre acontecimentos, o que sempre é marcado pela trajetória anterior de vida, que vai formando as lentes que modelam o que entendemos do que vemos.

Quanto à periodicidade, os diários nem sempre recebem atenção "diária", mas em períodos dados por acontecimentos, pela pertinência de um comentário em um determinado momento, pelo andamento de algum trabalho [...] Segundo Zabalza:

\footnotetext{
2 Blog é uma abreviação da junção das palavras inglesas web (rede) e log (diário de bordo onde os navegadores registravam os eventos das viagens). Granado, em seu blog (http://ciberjornalismo.com/oquesaoweblogs.htm), tenta, junto com outros espectadores-atores, montar um conceito de blog. Granado expõe que "um weblog é uma página com entradas datadas que aparecem pela ordem inversa em que foram escritas" e pede a opinião dos que por ali passam, agregando-se outros valores e perspectivas ao conceito. O conceito original passa a ser problematizado e, em certo momento, para facilitar, separam-no em duas partes: a "física" e de conteúdo. Fisicamente poderíamos dizer que os blogs são páginas com registros organizados em ordem cronológica, com possibilidades a interatividade. Pelo conteúdo, temos que são expressas opiniões pessoais (de uma pessoa ou grupo), com certo objetivo, sem passar por qualquer mediação ou censura, predominando a opinião do "dono".
} 
Os "diários" não têm por que ser uma atividade diária. Cumprem perfeitamente sua função (e sua realização se torna menos trabalhosa em tempo e esforço) mesmo que sua periodicidade seja menor: duas vezes por semana, por exemplo, variando os dias para que a narração seja mais representativa. $O$ importante é manter uma certa linha de continuidade na coleta e na redação das narrações (enfim, que não seja uma atividade intermitente, feita apenas de vez em quando e sem nenhuma sistematicidade). (ZABALZA, 2004, p.13).

Esta sistematicidade exigida pelos diários também exige certa disciplina e empenho do autor do $b l o g$, de modo que este olhe para os fatos com olhar inquieto, escreva fazendo uma leitura crítica dos acontecimentos, reflita sobre sua atuação. A escrita sistemática permite fazer uma leitura diacrônica sobre os acontecimentos e analisar a evolução dos fatos. Nestes casos, a reflexão acontece em períodos marcados por acontecimentos, que em certas horas inspiram mais análise do que em outras.

O que se nota no ciberespaço, ou mesmo no espaço dos blogs, é que tudo vai acontecendo a toda hora, que qualquer hora é passível de reflexão, sendo que alguns espaços e momentos inspiram mais uma ou outra atividade ou reflexão. No ciberespaço, a atribuição de sentidos é construída pela demanda, pelos interesses, pelas emergências, e não por uma sineta de escola que demarca certa parcela do conhecimento, uma espécie de ritual ou obrigação, como vemos muitas vezes no espaço escolar. Nota-se, inclusive, que muitas vezes as fronteiras entre os conhecimentos diluem-se expressivamente.

Dentre os autores que falam das potencialidades dos diários para a prática pedagógica, temos Porlán e Martín (1997), que nos apresentam os diários como um guia para a investigação, um instrumento para detectar problemas e explicitar concepções, para mudar/ permear concepções, como também para transformar a prática docente.

Porlán e Martín apresentam a investigação escolar como uma proposta intermediária entre o Modelo Tradicional e o Modelo Espontaneísta de Ensino. Seria embasada em princípios como a investigação dos alunos como processo de construção de normas, atitudes, destrezas e conhecimentos em aula; a investigação dos professores como forma de propiciar uma prática reflexiva e um desenvolvimento profissional permanente; o caráter processual, aberto e experimental dos currículos, como forma de estabelecer um equilíbrio adequado entre planejamento e avaliação do ensino. (PORLÁN y MARTÍN, 1997, p. 15).

O diário, nesta perspectiva, seria um recurso metodológico nucleador de todo esse processo. Sua utilização periódica permite refletir sobre o ponto de vista do autor e sobre os processos mais significativos da dinâmica em que está imerso. É um guia para reflexão sobre a prática, favorecendo a tomada de consciência do professor sobre seu processo de evolução sobre seus modelos de referência. Favorece, também, uma tomada de decisões mais fundamentadas. Por meio do diário, pode-se realizar focalizações sucessivas na problemática que se aborda, sem perder as referências ao contexto. Por último, propicia também o desenvolvimento dos níveis descritivos, analítico-explicativos e valorativos do processo de investigação e reflexão do professor. (PORLÁN y MARTÍN, 1997, p. 19-20).

Zabalza (2004) afirma que os diários podem ser empregados com a finalidade investigativa, bem como para orientar o desenvolvimento pessoal e profissional. Este autor apresenta como âmbitos de impacto formativo dos diários:

- o acesso ao mundo pessoal dos professores;

- os diários como recurso para explicitar os próprios dilemas em relação à atuação profissional;

- os diários como recurso de acesso à avaliação e ao reajuste de processos didáticos;

- os diários como recurso para o desenvolvimento profissional permanente.

De mais, a manutenção dos diários cria o hábito da reflexão, da sínese analítica e da escrita, além de facilitar o compartilhamento das ações e a troca de experiências. Dentre os principais autores que abortam esta temática, destacamos Schön (1983), Zeichner (1993) e Perrenoud (2002).

A reflexão da prática e na prática, como processo contínuo e de formação, aliada à troca de experiências, pode facilitar e tornar mais 
coerente as transformações do instituído, auxiliando na construção de uma nova epistemologia da prática, na construção de saberes e resoluções de problemas. Refletir na ação é olhar para ver o problema, observar a reação dos alunos e utilizar isso para ajustar as ações no momento em que o problema é notado. A reflexão sobre $a$ (da) ação ocorre antes da aula, quando fazemos o planejamento, e depois, quando consideramos o que aconteceu.

Essa atitude disposta à transformação do instituído é viabilizada pela postura investigativa, curiosa, questionadora, inquieta e prática reflexiva. Escrevendo e conversando com outros profissionais, o professor pode clarificar seus problemas e planejar de um modo mais adequado. A reflexão ajuda a pôr juntos pedaços para formar uma educação mais efetiva (PETERS, 2004).

A insatisfação da prática pode ser promissora no sentido de motivar o professor para refletir, observar os alunos, sua postura, a escola; buscar leituras de autores e tentar "ler" a realidade. A reflexão, ao contrário da ação-rotina, implica em um espírito aberto, disposto a falar e a ouvir com sinceridade, com um espírito de responsabilidade, ciente de seu compromisso político (DEWEY, 1959; ZEICHNER, 1993; KINCHELOE, 1997). Ao repensar a prática, o professor está olhando para quem está direcionado seus esforços, o que essas pessoas querem e precisam, como atingir objetivos. Um trabalho transformador, disposto a questionar-se, avaliar-se e reformular a prática (HYPOLITTO, 2005).

Reiman (1999) defende que a prática reflexiva passa pela descrição, análise, explanação e reflexão. Isto se traduz em contar como ocorre o processo de ensino-aprendizagem (ver, clarificar os problemas), pensar em soluções/alternativas para os problemas, examinando o que é efetivo ou não, comunicar (oral ou escrita) os efeitos desse processo, além de identificar os significados e as significações da prática. Isso só é possível quando é criada/estabelecida uma cultura de reflexão na e sobre a ação (SCHÖN, 1983).

\section{Blogs como diários da prática pedagógica: comunicação, autoria e reflexão}

Desencadear o processo de reflexão pela escrita não é simples. Demanda tempo, esforço e, principalmente, quebra a apatia acrítica frente aos fatos. Esta apatia é construída e reforçada em vários momentos da nossa vida, tais como na escola, quando somos incentivados a copiar e repetir em vez de criar.

Nesta vivência, um dos pontos mais difíceis foi a criação da cultura do escrever e do pensar, observar e refletir sobre o que acontece com nós e ao nosso redor. Isso foi mais difícil, inclusive, com a tecnologia desconhecida: de 25 alunos, apenas um sabia o que era um blog (diário eletrônico). Porém, isso não representou uma barreira, pois em poucos instantes todos já conseguiam realizar as atividades básicas.

Outro ponto que dificultou a reflexão em blogs foi o acesso: muitos alunos tinham acesso a computador com internet somente no horário da aula. Como já explicitado por Zabalza (2004), a reflexão em diários se dá por uma periodicidade por acontecimentos. Mas como manter uma sistematicidade de reflexão em diários eletrônicos se temos acesso ao meio eletrônico somente eventualmente?

Uma das vantagens de realizar os diários em meio eletrônico é poder acoplar às potencialidades dos diários às possibilidades da web. Mas isso perde o sentido quando os alunos são obrigados a fazer os registros no suporte analógico (papel) para depois "passar a limpo" no digital (web). Quando a construção acontece no ambiente digital, há uma facilidade muito maior em operar diferentes informações, há também a ampliação do universo presente, sendo que a informação representada no diário é o resultado do trânsito em diferentes espaços e da interação entre diferentes objetos. No ambiente digital, a informação também deixa de ser palavras para se tornar dados que formam imagens, hipertextos, áudio, pontos de interação (enquetes, comentários...), o que enriquece muito mais a produção e a reflexão sobre os fatos.

À medida que ocorre este transitar em diferentes espaços, a reflexão deixa de ser um processo particular meu (do indivíduo). A reflexão é publicizada e compartilhada para que outros interajam com suas formas de ver e representar o mundo, comparando assim opiniões e abrindo espaço para outras construções. Assim, a reflexão passa a ser um processo coletivo. Na verdade, a construção do pensamento, sendo ele registrado em qualquer que seja o suporte, sempre se deu de 
forma coletiva, influenciada por todo o contexto que o indivíduo vive. Porém, isto se torna muito mais explícito e potencializado quando registrado/ disponibilizado no suporte web.

Como Bonilla (2005) aponta, o registro escrito possibilita que a palavra seja lida e entendida em outros locais e tempos, sem a necessidade da presença física do sujeito que a compôs, ampliando assim sua disseminação. Com os blogs, os sujeitos envolvidos nesta atividade vivenciaram a extrapolação do espaço-tempo da escola, uma vez que o fazer pedagógico se tornou um continuum prolongado pela reflexão, compartilhada com outros sujeitos, construída e reconstruída com outros objetos e espaços.

Por que realizar esta ação com os alunos de Ciências Naturais? Qual a importância desta prática para estes sujeitos? As ditas ciências "puras" vivem de forma muito arraigada a valorização do conhecimento científico, o que, na escola, se traduz nas verdades ditadas pelos livros (didáticos). Delizoicov et al. (2002) apontam para a necessidade da consideração dos saberes prévios, das muitas esferas extra-escolares que auxiliam na construção do conhecimento, confrontado de forma crítica e problematizadora com os saberes escolares, os conceitos científicos. Estes alunos envolvidos nesta atividade vivenciaram a autoria: eles eram os autores daquelas informações ali presentes, que poderiam ser lidas por pessoas em qualquer parte do mundo. Ali seus saberes estavam sendo valorizados, tendo também a oportunidade de confrontá-los com os conceitos apresentados em livros ou em inúmeros sítios da internet. Gerou-se assim uma produção refletida, articulada, contextualizada, coerente com a realidade global e local vivenciada por estes alunos.

Porém, isso só é possível se estivermos dispostos a alterar alguns saberes postos na educação. Por várias vezes, eu, enquanto professora, vivenciei alguns dilemas, tais como:

- como o processo era muito individualizado, exigia de mim atenção a cada sujeito, e não a uma massa homogênea de seres sem luz. Porém educação não é comunicação em massa, isso nos aponta que devemos repensar alguns conceitos;

- por outro lado, quem disse que ler e comentar todos os diários deve ser "função" única do professor? Pensar isso significa reiterar o modelo que diz que o professor é o máximo detentor da verdade. O que notamos contemporaneamente é exatamente o contrário: redes retroalimentadas, descentralizadas, com centros flutuantes. No segundo semestre de atuação desta prática, incumbiu-se todos os alunos de lerem, revisarem, comentarem, expressarem suas opiniões sobre as escritas dos colegas, o que descentralizou a palavra e tornou este processo muito mais rico;

- um dos benefícios do uso dos blogs neste contexto é a avaliação processual: pode ser efetuada a leitura progressiva com um constante feedback, possibilitando reconstruções durante o processo e não em pontos específicos (provas) que não auxiliam o aluno na construção do conhecimento e só funcionam como ferramenta de coerção.

Por tudo isso, indicamos aqui que os blogs podem servir como ferramenta de suporte ao registro e reflexão da prática docente, com várias potencialidades associadas e dinâmicas. Os blogs, neste contexto, indicaram a comunicação e as mídias digitais como fundamentais na formação de professores, deixando emergir novas práticas sociais. Porém, para que estes movimentos tomem a proporção desejada, é necessário repensar alguns paradigmas e deixar que a educação seja permeada por outras formas de conhecer e comunicar, para que assim reverberem em outras formas de atuar e pensar a e na educação.

\section{Referências}

Blog: Ensino de ciências. Disponível em: <http://edc270.blogspot.com> Acesso em: 08 mar. 2005.

BONILLA, Maria Helena. Escola aprendente: para além da Sociedade da Informação. Rio de Janeiro: Quartet, 2005. 
DELIZOICOV, Demétrio; ANGOTTI, José André; PERNAMBUCO, Marta Maria. Ensino de ciências: fundamentos e métodos. São Paulo: Cortez, 2002. (Coleção Docência em Formação)

DEWEY, John. Como pensamos. São Paulo: Nacional, 1959.

HYPOLITTO, Dinéia. O professor como profissional reflexivo. Disponível em: <http:// www.usjt.br/col_prof/008_prof_reflexivo.phtml>. Acesso em: 08 mar. 2005.

KINCHELOE, Joe L. A formação do professor como compromisso político: mapeando o pósmoderno. Porto Alegre: Artes Médicas, 1997.

PERRENOUD, Philippe. A prática reflexiva no ofício de professor: profissionalização e razão pedagógica. Porto Alegre: Artmed, 2002.

PETERS, Valley. Inquire Within: Reflective Practice in Teaching. Teton Literacy Program: COABE, April 28, 2004. Disponível em: $<$ www.coabe 04 .org/conferencedocs/ 20040428_Inquire_VPeters_Presentationhandout.doc>. Acesso em: 08 mar. 2005.
PORLÁN, Rafael; MARTín, José. El diario del professor: un recurso para la investigación en el aula. Sevilla: Díada, 1997.

REIMAN, A. J. Guided reflective practice. N.C. State University: Raleigh, 1999. Disponível em: <http://goknow.com/golead/articles/ reflective.html>. Acesso em: 06 set. 2004.

SCHÖN, Donald. The reflective practitioner: how professional think in action. New York: Basic Books, 1983.

ZABALZA, Miguel A. Diários de aula: um instrumento de pesquisa e desenvolvimento profissional. Porto Alegre: Artmed, 2004.

ZEICHNER, Kenneth. A formação reflexiva de professores: idéias e práticas. Lisboa: Educa, 1993.

Recebido: 10/12/2006 Aceito: 08/02/2007 